\title{
MORFOGÊNESE DE Trachypogon vestitus SUBMETIDO À QUEIMA, DURANTE O PERÍODO SECO, NOS CERRADOS DE RORAIMA
}

\author{
Newton de Lucena Costa, ${ }^{1}$ Vicente Gianluppi, ${ }^{2}$ Anibal De Moraes ${ }^{3}$ \\ ${ }^{1}$. Eng. Agr., M.Sc., Embrapa Roraima, Doutorando em Agronomia/Produção Vegetal, UFPR, Curitiba, PR, Brasil - \\ newton@cpafrr.embrapa.br \\ ${ }^{2}$. Eng. Agr., M.Sc., Embrapa Roraima, Boa Vista, RR, Brasil \\ ${ }^{3}$. Eng. Agr., D.Sc., Professor Associado II, UFPR, Curitiba, PR, Brasil
}

O efeito da idade de rebrota $(21,28,35,42,49,56,63$ e 70 dias) sobre a produção de forragem e características morfogênicas e estruturais de Trachypogon vestitus, submetido à queima, durante o período seco, foram avaliados em condições de campo. $\mathrm{O}$ delineamento experimental foi inteiramente casualizado com três repetições. As avaliações foram realizadas no período de dezembro de 2009 a fevereiro de 2010. O aumento da idade de rebrota resultou em maiores rendimentos de matéria seca (MS), taxa absoluta de crescimento (TAC), número de perfilhos/planta (NPP), número de folhas/perfilho (NFP), tamanho médio de folhas (TMF), área foliar e taxas de expansão e senescência foliar $(\mathrm{P}<0,05)$. As relações entre idades de rebrota, rendimento de MS, TAC, NPP, NFP e TMF da gramínea foram ajustadas ao modelo quadrático de regressão, sendo os valores máximos registrados aos 64,$8 ; 42,3 ; 59,6 ; 61,8$ e 59,4 dias de rebrota, respectivamente. As taxas de crescimento da cultura, taxa de crescimento relativo, taxas de aparecimento de perfilhos e de folhas foram inversamente proporcionais às idades das plantas.

PALAVRAS-CHAVE: folhas; idade da planta; matéria seca; morfogênese; perfilhamento.

\section{MORPHOGENESIS OF Trachypogon vestitus UNDER BURNING EFFECT, DURING DRY SEASON, IN RORAIMA'S SAVANNAS}

\section{ABSTRACT}

The effects of plant regrowth age $(21,28,35,42,49,56$, 63 and 70 days) on dry matter (DM) yield, and morphogenetic and structural characteristics of Trachypogon vestitus, submitted to burning, during dry season, were evaluated under natural field conditions. The experimental design was completely randomized, with three replications. Evaluations were carried out during the period from December 2009 to February 2010. DM yields, absolute growth rate, number of tillers/plant (NTP), number of leafs/plant (NLP), leaf area, leaf senescence and elongation rates and blade length (BL) increased consistently with growth stage $(\mathrm{P}<.05)$. The relations among DM yield, forage production rate, NTP, NLP and BL with plants regrowth age were described by the quadratic regression model and the maximum values were estimated at $64.8 ; 42.3 ; 59.6 ; 61,8$ and 59.4 days of regrowth, respectively. The crop growth and relative growth rates, tiller and leaf appearance rates were inversely proportional to plant age.

KEYWORDS: dry matter; leaves; morphogenesis; plant age; tillering. 


\section{INTRODUÇÃO}

Nos cerrados de Roraima, as pastagens nativas representam a fonte mais econômica para alimentação dos rebanhos. No entanto, face às oscilações climáticas, a produção de forragem durante o ano apresenta flutuações estacionais, ou seja, abundância no período chuvoso (abril a setembro) e déficit no período seco (outubro a março), o que afeta negativamente os índices de produtividade animal (BRAGA, 1998; GIANLUPPI et al., 2001). Apesar de limitações quantitativas e qualitativas, historicamente, as pastagens nativas proporcionaram o suporte alimentar para a exploração pecuária, que passou a se constituir, ao longo dos anos, como a principal atividade econômica de Roraima (COSTA et al., 2008a,b). O sistema de pastejo contínuo com taxa de lotação variável, mas em geral extensivo e desvinculado do ritmo produtivo estacional, tem contribuição direta para os baixos índices produtivos dos rebanhos.

Como forma de melhorar as condições de alimentação, os criadores usam a queima como prática de manejo das pastagens visando à eliminação da forragem não consumida e senescida, proporcionando melhoria no seu valor nutritivo quando em estádios iniciais de crescimento, período em que a gramínea apresenta-se mais tenra. Nas pastagens nativas dos cerrados de Roraima, onde a gramínea Trachypogon vestitus representa entre $30 \mathrm{e}$ $50 \%$ de sua composição botânica, a produção animal pode ser muito baixa, o que inviabiliza economicamente a atividade pecuária, desde que não sejam implementadas práticas para o seu melhoramento (GIANLUPPI et al., 2001). No entanto, são poucas as pesquisas sobre as suas características morfogênicas e estruturais, visando à proposição de práticas de manejo mais sustentáveis.

O estádio de crescimento em que a planta é colhida afeta diretamente o rendimento, a composição química, a capacidade de rebrota e a sua persistência. Em geral, pastejos menos frequentes fornecem maiores produções de forragem; contudo, ocorrem decréscimos acentuados em sua composição química, reduções na relação folha/colmo e, consequentemente, menor consumo pelos animais (GRANT et al., 1981; COSTA et al., 2011). A produtividade de gramíneas forrageiras decorre da contínua emissão de folhas e perfilhos, processo importante para a restauração da área foliar após corte ou pastejo e que assegura a sua perenidade. Os processos de formação e desenvolvimento de folhas são fundamentais para o crescimento vegetal, considerando-se a sua importância para a fotossíntese, ponto inicial para a formação de novos tecidos (LEMAIRE, 2001; GOMIDE et al., 2006).

A morfogênese de uma gramínea durante seu crescimento vegetativo pode ser descrita por três variáveis: a taxa de aparecimento, a taxa de alongamento e a duração de vida das folhas, as quais, apesar de sua natureza genética, são fortemente influenciadas pelas condições ambientais (temperatura, luz, água e fertilidade do solo) e práticas de manejo. As interações entre essas variáveis determinam as características estruturais número de folhas vivas/perfilho (NFV), tamanho final de folhas (TFF) e densidade de perfilhos - as quais irão determinar o índice de área foliar (IAF), ou seja, o aparato utilizado para a interceptação da radiação pelo dossel da pastagem. O NFV é decorrente da taxa de aparecimento e a duração de vida das folhas, sendo determinado geneticamente, enquanto que a taxa de alongamento foliar condiciona o TFF (CHAPMAN \& LEMAIRE, 1993). O conhecimento das características morfogênicas e estruturais proporciona uma visualização da curva estacional de produção de forragem e uma estimativa de sua qualidade (GOMIDE, 1994), além de permitir a proposição de práticas de manejo específicas para cada gramínea forrageira (LEMAIRE, 2001; GOMIDE et al., 2006).

Neste trabalho foram avaliados os efeitos da idade de rebrota sobre a produção de forragem e características morfogênicas e estruturais de Trachypogon vestitus, após a queima, durante o período seco, nos cerrados de Roraima.

\section{MATERIAL E MÉTODOS}

O experimento foi conduzido em uma pastagem nativa de $T$. vestitus, localizada em Boa Vista, Roraima $\left(60^{\circ} 43^{\prime}\right.$ de longitude oeste e $2^{\circ} 45^{\prime}$ de latitude norte), a qual era submetida à queima anual em meados do período seco (novembro). O clima da região, segundo a classificação de Köppen, é Awi, caracterizado por períodos seco e chuvoso bem definidos. A precipitação anual é de $1.600 \mathrm{~mm}$, sendo que $80 \%$ ocorrem nos meses do período 
chuvoso (abril a setembro). O período experimental foi de dezembro de 2009 a fevereiro de 2010, o qual corresponde à estação seca, sendo a precipitação acumulada de $48,6 \mathrm{~mm}$.

O solo da área experimental é um Latossolo Amarelo, textura média, com as seguintes características químicas, na profundidade de 0-20 cm: $\mathrm{pH}_{\mathrm{H} 2 \mathrm{O}}=4,8 ; \mathrm{P}=1,8 \mathrm{mg} / \mathrm{kg} ; \mathrm{Ca}+\mathrm{Mg}=0,90$ $\mathrm{cmol}_{\mathrm{c}} \cdot \mathrm{dm}^{-3} ; \mathrm{K}=0,01 \mathrm{cmol}_{\mathrm{c}} \cdot \mathrm{dm}^{-3} ; \mathrm{Al}=0,61 \mathrm{cmol}_{\mathrm{c}} \mathrm{dm}^{-}$ ${ }^{3} ; \mathrm{H}+\mathrm{Al}=2,64 \mathrm{cmol}_{\mathrm{c}} \cdot \mathrm{dm}^{-3} ; \mathrm{SB}=0,91 \mathrm{cmol}_{\mathrm{c}} \cdot \mathrm{dm}^{-3} \mathrm{e} \mathrm{V}$ $=25,6 \%$. $\mathrm{O}$ delineamento experimental foi inteiramente casualizado com três repetições, sendo os tratamentos constituídos por oito idades de rebrota $(21,28,35,42,49,56,63$ e 70 dias após a queima da pastagem). O tamanho das parcelas foi de 2,0 x 2,0 $\mathrm{m}$, sendo a área útil de $1,0 \mathrm{~m}^{2}$.

Os parâmetros avaliados foram rendimento de matéria seca (MS), taxa absoluta de crescimento (TAC), taxa de aparecimento de perfilhos (TAP), taxa de crescimento da cultura (TCC), taxa relativa de crescimento (TCR), número de perfilhos/planta (NPP), número de folhas/perfilho (NFP), taxa de aparecimento de folhas (TAF), taxa de expansão foliar (TEF), taxa de senescência foliar (TSF), tamanho médio de folhas (TMF) e área foliar/perfilho (AF). Com exceção dos rendimentos de MS que foram determinados em toda a área útil da parcela, para as demais variáveis as avaliações foram realizadas em quatro touceiras/parcela, selecionadas em função de suas alturas e diâmetros, de modo a representar a variabilidade da população de plantas em cada parcela.

A TAC e a TAP foram obtidas dividindo-se o rendimento de MS e o número de perfilhos pelo respectivo período de rebrota. A TCC foi estimada pela fórmula: $\mathrm{TCC}=\left(\mathrm{P}_{2}-\mathrm{P}_{1}\right) /\left(\mathrm{T}_{2}-\mathrm{T}_{1}\right)$, onde $\mathrm{P}_{1}$ e $\mathrm{P}_{2}$ representam a produtividade de $\mathrm{MS}$ de duas amostragens sucessivas ( $\mathrm{kg}$ de MS/ha) e $\mathrm{T}_{1}$ e $\mathrm{T}_{2} \mathrm{O}$ intervalo de tempo, em dias, transcorrido entre a obtenção das amostragens. A TCR foi obtida pelo uso da expressão: TCR $=\left(\operatorname{LnP}_{2}-\operatorname{LnP}_{1}\right) /\left(\mathrm{T}_{2}-\mathrm{T}_{1}\right)$, onde $\mathrm{LnP}_{1}$ e $\mathrm{LnP}_{2}$ são os valores de logaritmos da MS de duas amostragens sucessivas e $T_{1}$ e $T_{2}$ o intervalo de tempo, em dias, transcorrido entre as amostragens. A TEF e a TAF foram calculadas dividindo-se o comprimento acumulado de folhas e o número total de folhas no perfilho, respectivamente, pelo período de rebrota. O TMF foi determinado pela divisão do alongamento foliar total do perfilho pelo seu número de folhas. Para o cálculo da AF utilizouse a fórmula da área do triângulo (altura $\mathrm{x}$ base/2) e, para tanto, foram anotados o comprimento e a largura de todas as folhas dos perfilhos das touceiras amostrados. A TSF foi obtida dividindo-se o comprimento das folhas necrosadas pela idade de rebrota.

O filocrono, intervalo de tempo térmico para o aparecimento de duas folhas sucessivas, foi determinado como o inverso do coeficiente angular da regressão entre o número de folhas e a soma térmica (graus.dia - GD) observada durante o período experimental (70 dias). Para o cálculo do acúmulo de GD foi considerada a temperatura mínima basal da planta de $10^{\circ} \mathrm{C}$, utilizando-se a fórmula: $\mathrm{GD}=(\mathrm{TM}-\mathrm{Tm} / 2)+(\mathrm{Tm}-\mathrm{Tb})$, onde, $\mathrm{TM}=$ temperatura máxima do ar $\left({ }^{\circ} \mathrm{C}\right) ; \mathrm{Tm}=$ temperatura mínima do ar $\left({ }^{\circ} \mathrm{C}\right)$ e $\mathrm{Tb}=$ temperatura mínima basal da planta $\left({ }^{\circ} \mathrm{C}\right)$.

Os dados foram submetidos à análise de variância e de regressão considerando-se o nível de significância de 5\% de probabilidade, utilizando-se o programa SISVAR. Para se estimar a resposta dos parâmetros avaliados às idades de rebrota, a escolha dos modelos de regressão baseou-se na significância dos coeficientes linear e quadrático, por meio do teste " $\mathrm{t}$ ", de Student, a 5\% de probabilidade.

\section{RESULTADOS E DISCUSSÃO}

Os rendimentos de MS e as TAC foram significativamente $(\mathrm{P}<0,05)$ incrementados com a idade das plantas, sendo as relações quadráticas e os valores máximos estimados aos 64,8 e 42,3 dias de rebrota, respectivamente (Figuras 1 e 2). Os valores registrados neste trabalho foram semelhantes aos relatados por MOCHIUTTI et al. (2000a,b), avaliando a disponibilidade de forragem de Trachypogon plumosus, em pastagens nativas dos cerrados do Amapá (1.124 e 1.417 kg/ha de MS, respectivamente, para pastagens roçadas ou queimadas anualmente), porém inferiores aos reportados por MATA et al. (1985), na Venezuela, para pastagens de Trachypogon spp., submetidas a diferentes intervalos entre cortes $(1.654 ; 2.309$ e $2.631 \mathrm{~kg}$ de $\mathrm{MS} / \mathrm{ha}$, respectivamente para cortes a cada 28, 49 e 63 dias). 


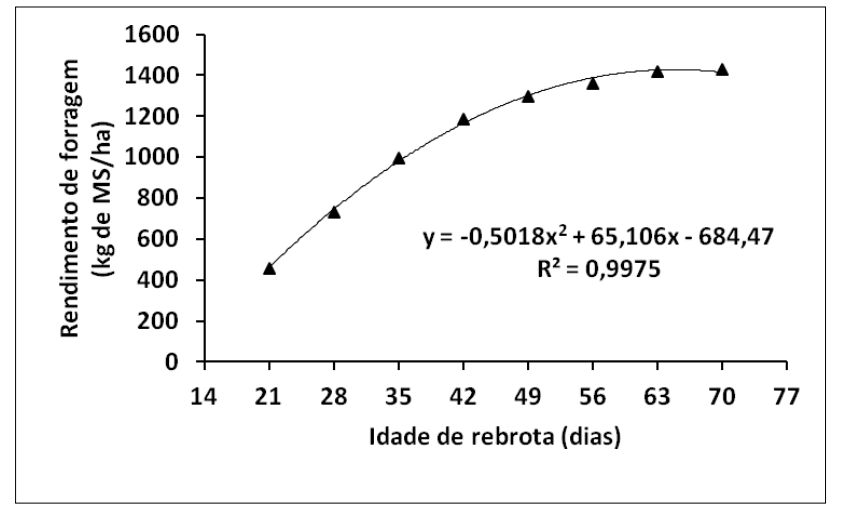

FIGURA 1. Rendimento de forragem de Trachypogon vestitus, em função das idades de rebrota.

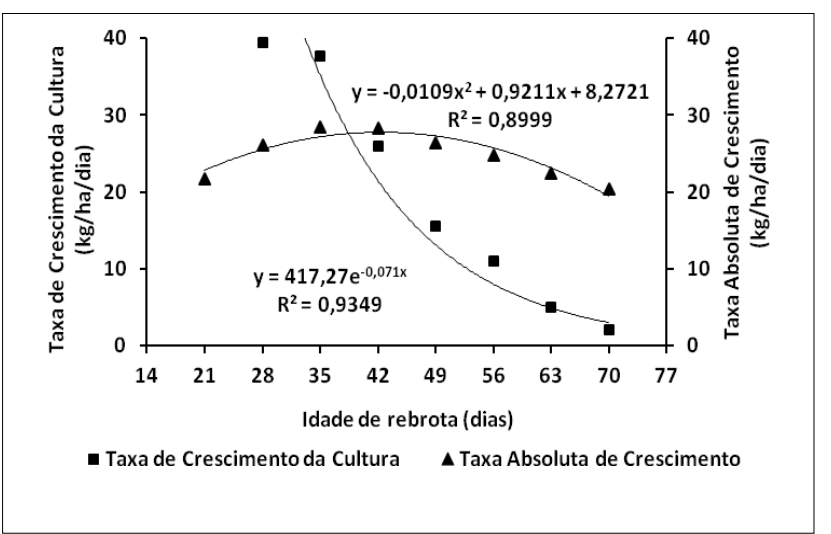

FIGURA 2. Taxa absoluta de crescimento e taxa de crescimento da cultura de Trachypogon vestitus, em função das idades de rebrota.

Os efeitos da idade das plantas sobre a TCC e a TCR foram ajustados ao modelo exponencial (Figuras 2 e 3). Os maiores valores foram registrados no período entre 28 e 42 dias de rebrota, os quais foram semelhantes aos reportados por TEJOS (2002) para pastagens de Trachypogon spp., submetidas a uma queima anualmente $(29,88 \mathrm{~kg} / \mathrm{ha} / \mathrm{dia}$ e 0,0319 g.g/dia). As altas taxas de crescimento, durante os períodos iniciais de rebrota, representam um mecanismo de adaptação da gramínea, pois, ao se reduzir o tempo para que ocorra a máxima interceptação da radiação solar incidente, promovese uma melhor utilização da água devido ao sombreamento mais rápido do solo, o que favorece sua competitividade intraespecífica (LEMAIRE, 2001).

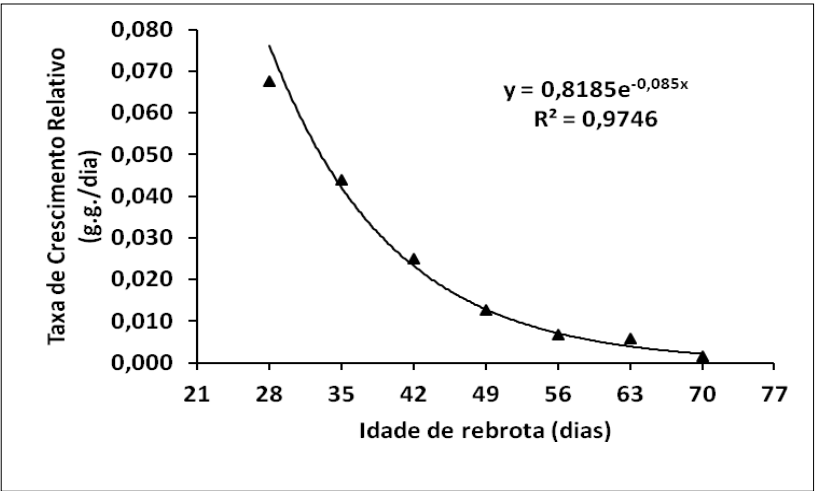

FIGURA 3. Taxa de crescimento relativo de Trachypogon vestitus, em função das idades de rebrota.

A TAP foi inversamente proporcional às idades das plantas (Figura 4). Em pastagens de Brachiaria decumbens, SANTOS et al. (2010) constataram reduções na TAP, em função da idade das plantas $\left(17,7 ; 16,8\right.$ e 8,82 perfilhos $/ \mathrm{m}^{2}$.dia, respectivamente para 73, 95 e 115 dias de rebrota). $\mathrm{O}$ NPP e o NFP foram ajustados ao modelo quadrático de regressão e os máximos valores registrados aos 59,6 e 61,8 dias de rebrota (Figuras 5 e 6). Os valores registrados neste trabalho para a TAP, o NPP e o NFP foram superiores aos reportados por COSTA et al. (2008a) para T. plumosus, submetido a intervalos entre cortes de 45 dias $(0,112$ perfilho/dia, 5,05 perfilhos/planta e 7,08 folhas/perfilho). As correlações entre o rendimento de MS e o NPP ( $\mathrm{r}=$ $0,9618 ; \mathrm{P}=0,0014)$ e o NFP $(\mathrm{r}=0,9850 ; \mathrm{P}=0,0031)$ foram positivas e significativas, as quais explicaram os incrementos em, respectivamente, 92,5 e $97,05 \%$ verificados nos rendimentos de forragem da gramínea, em função das idades de corte.

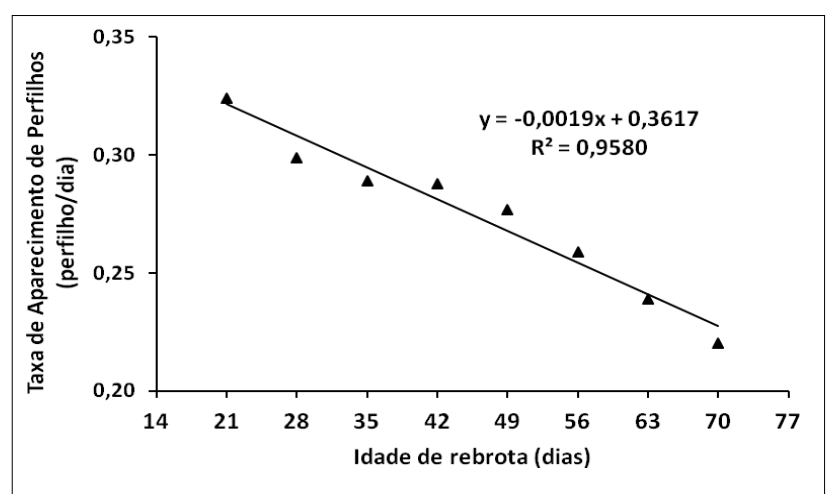

FIGURA 4. Taxa de aparecimento de perfilhos de Trachypogon vestitus, em função das idades de rebrota. 


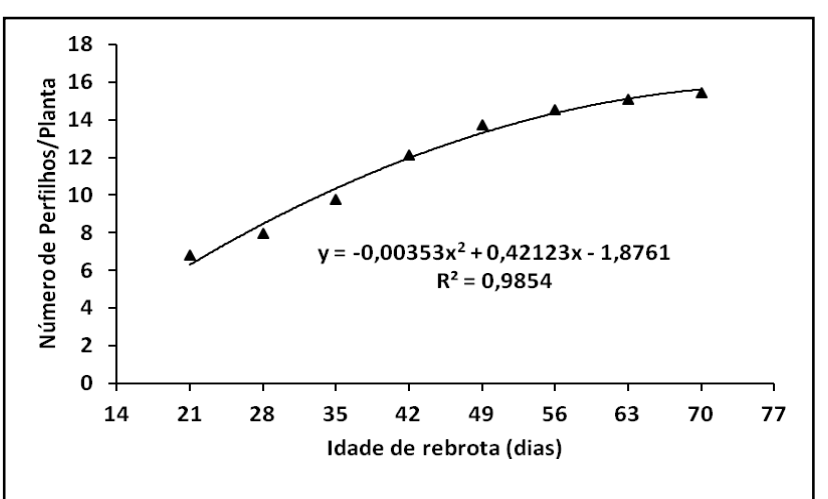

FIGURA 5. Número de perfilhos/planta de Trachypogon vestitus, em função das idades de rebrota.

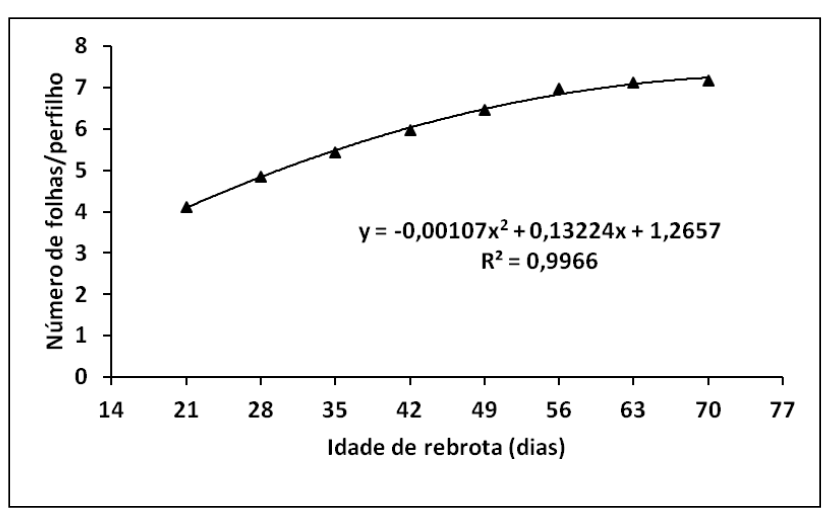

FIGURA 6. Número de folhas/perfilho de Trachypogon vestitus, em função das idades de rebrota.

O potencial de perfilhamento de um genótipo, durante o estádio vegetativo, depende de sua velocidade de emissão de folhas, as quais produzirão gemas potencialmente capazes de originar novos perfilhos, dependendo das condições ambientais e das práticas de manejo adotadas (LEMAIRE \& CHAPMAN, 1996). Em relvados densos, o ambiente luminoso afeta a competição entre plantas, por meio da quantidade e qualidade de luz incidente e da relação vermelho:vermelho extrema. Quando a luz penetra no dossel, atenua-se a luz vermelha e a que alcança a base da planta é predominantemente vermelha extrema, caracterizada como fotossinteticamente ineficiente, promovendo redução na produção de perfilhos, notadamente os de ordem elevada (BALLARÉ et al., 1987). A TAP foi negativamente correlacionada com o NPP $(\mathrm{r}=$ $0,8221 ; \mathrm{p}=0,0122)$ e o NFP $(\mathrm{r}=-0,8772 ; \mathrm{p}=0,0041)$, evidenciando o efeito restritivo da luminosidade na porção inferior das plantas, o qual foi acentuado com o aumento do período de rebrota.
$\mathrm{O}$ efeito da idade de rebrota sobre o TMF foi ajustado ao modelo quadrático e o máximo valor registrado aos 59,4 dias de rebrota (Figura 7). O tamanho e o ângulo de inserção das folhas têm implicação na distribuição e qualidade da luz dentro do dossel, afetando a modulação do crescimento das plantas através da produção de fotoassimilados nas fontes e sua alocação aos drenos. Folhas pequenas podem ser fundamentais no início do crescimento, pois facilitam a maior penetração da radiação vermelha em detrimento da vermelha extrema, implicando melhor qualidade de luz para a realização da fotossíntese pelas folhas situadas na porção inferior da planta (LEMAIRE, 2001).

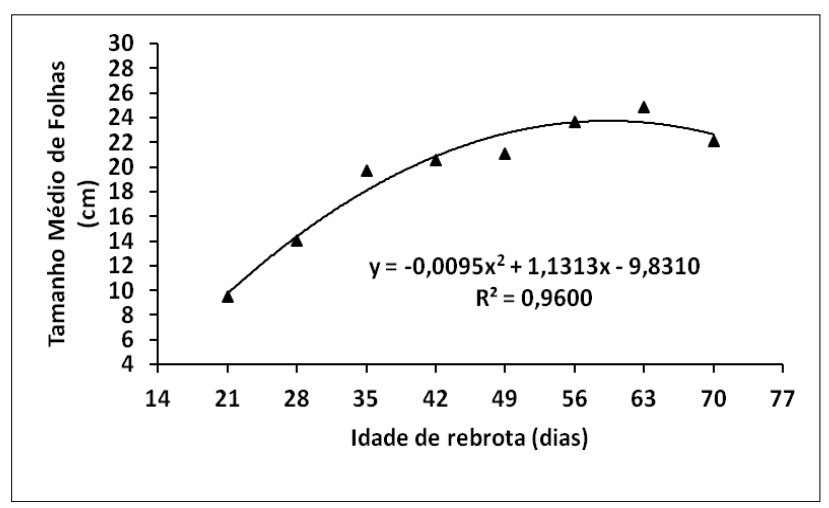

FIGURA 7. Tamanho médio de folhas de Trachypogon vestitus, em função das idades de rebrota.

A AF foi diretamente proporcional às idades das plantas, ocorrendo o inverso quanto à TAF (Figuras 8 e 9), enquanto que para a TEF a relação foi quadrática e o máximo valor registrado aos 46,9 dias de rebrota (Figura 10). A AF, TAF e a TEF obtidas neste trabalho, para a maioria das idades das plantas, foram semelhantes às reportadas para $T$. plumosus encontradas por COSTA et al. (2008b), que estimaram valores médios de $56,15 \mathrm{~cm}^{2} /$ perfilho; 0,157 folhas/perfilho.dia e 2,50 cm/perfilho.dia, para plantas aos 45 dias de rebrota. Gramíneas com maior habilidade competitiva são aquelas que desenvolvem uma arquitetura mais eficiente na interceptação de luz, através da rápida expansão de área foliar e colonização da camada superior do dossel, em decorrência do alongamento da bainha e entrenós do colmo (LEMAIRE, 2001). 


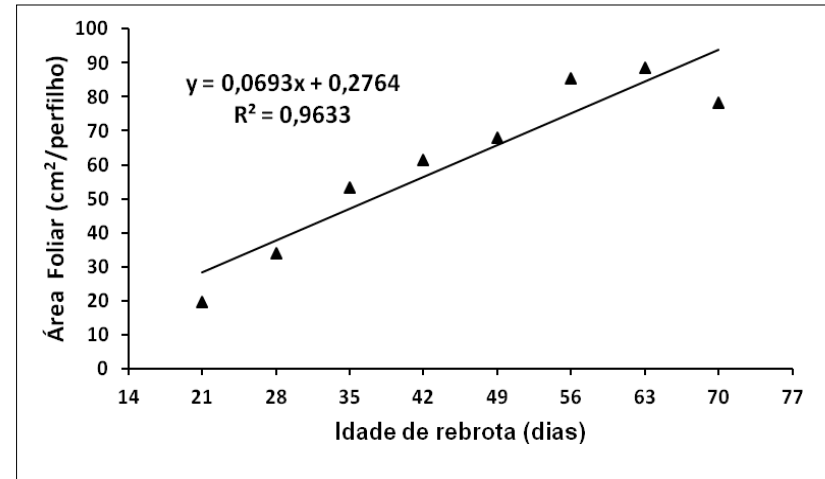

FIGURA 8. Área foliar de Trachypogon vestitus, em função das idades de rebrota.

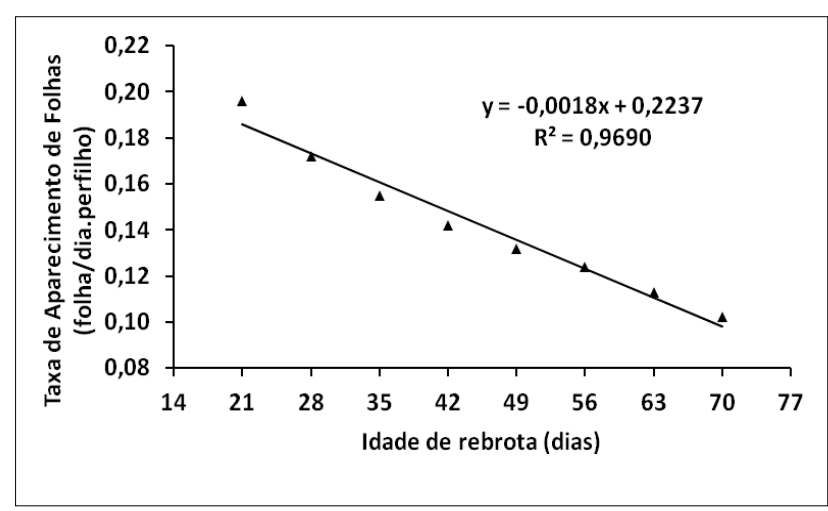

FIGURA 9. Taxa de aparecimento de folhas de Trachypogon vestitus, em função das idades de rebrota.

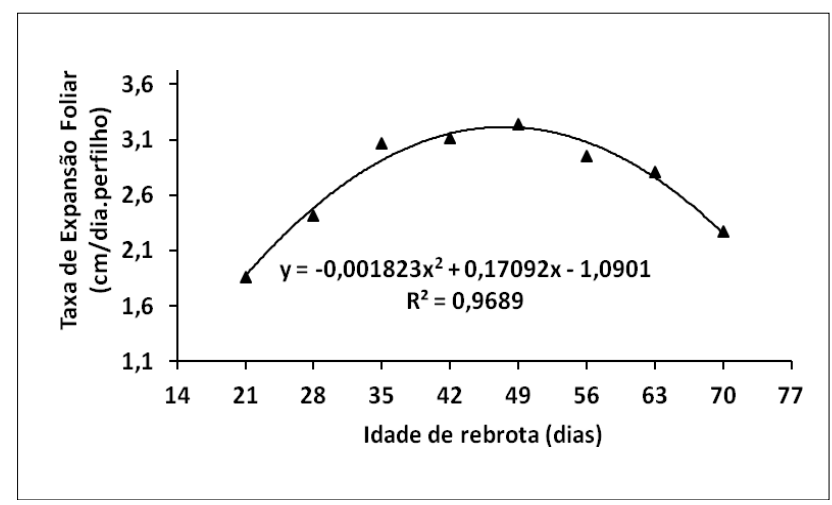

FIGURA 10. Taxa de expansão foliar de Trachypogon vestitus, em função das idades de rebrota.

A TAF é a característica morfogênica que merece maior destaque, pois afeta diretamente o tamanho da folha, a densidade populacional de perfilhos e o número de folhas/perfilho (HORST et al., 1978). As TAF e TEF apresentam uma correlação negativa, indicando que quanto maior a TAF, menor será o tempo disponível para o alongamento das folhas (COSTA et al., 2008a,b). Neste trabalho, a correlação entre essas duas variáveis foi negativa e não significativa $(\mathrm{r}=$ 0,4394; $\mathrm{p}=0,2759$ ). GRANT et al. (1981) observaram que a TEF foi positivamente correlacionada com a quantidade de folhas verdes remanescentes no perfilho após a desfolhação, sendo o tamanho do perfilho o principal responsável pela longa duração da TEF. MESQUITA \& NERES (2008) verificaram uma relação inversa entre TAF e TMF, sendo o menor ritmo de aparecimento de folhas maiores decorrente do maior percurso dentro da bainha desde a emergência até a completa expansão da folha. Neste trabalho, a correlação entre TMF e TAF foi negativa e significativa $(r=-0,9309$; $\mathrm{p}=0,0012$ ).

A relação entre TSF e as idades de rebrota foi linear e o processo de senescência constatado a partir dos 28 dias de rebrota (Figura 11). Os valores registrados neste trabalho foram inferiores aos que COSTA et al. (2008b) reportaram para T. plumosus, durante o período chuvoso, ao estimarem uma TSF de $0,342 \mathrm{~cm} /$ perfilho.dia, para plantas avaliadas aos 45 dias de rebrota. A senescência foliar reduz a disponibilidade de forragem de melhor qualidade, sendo causada pela competição por metabólitos e nutrientes entre as folhas velhas e as jovens em crescimento (LEITE et al., 1998). A senescência é um processo natural que caracteriza a última fase de desenvolvimento de uma folha, iniciada após sua completa expansão, cuja intensidade se acentua progressivamente com o aumento da área foliar, em decorrência do sombreamento das folhas inseridas na porção inferior do colmo (PARSONS \& CHAPMAN, 2000). Apesar do efeito negativo sobre a qualidade da forragem, a senescência representa um importante processo fisiológico no fluxo de tecidos da gramínea, pois cerca de $50 \%$ do carbono e $80 \%$ do nitrogênio são reciclados das folhas senescentes e utilizados para a produção de novos tecidos foliares (CARRÈRE et al., 1997; LEMAIRE \& AGNUSDEI, 2000).

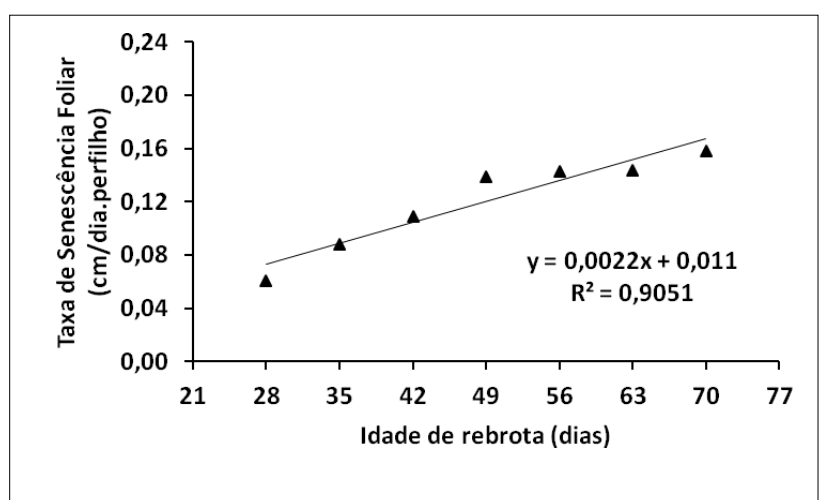

FIGURA 11. Taxa de senescência foliar de Trachypogon vestitus, em função das idades de rebrota. 
A relação entre o número de folhas/perfilho e a soma térmica foi linear e descrita pela equação: Y $=3,7374+0,00397 \mathrm{GD}\left(\mathrm{r}^{2}=0,8957\right)$. O filocrono foi estimado em 251,9 GD, o qual foi superior ao reportado por TRINDADE \& ROCHA (2001) para Andropogon lateralis (205 GD), gramínea nativa da Depressão Central do Rio Grande do Sul, porém inferior ao constatado por TOWNSEND (2008) para Paspalum guenoarum biótipo Azulão (275 GD), durante o outono e submetido a diferentes doses de nitrogênio $(0,60,180,360 \mathrm{~kg}$ de N/ha). Em termos práticos, quanto menor o filocrono, mais eficiente é a gramínea na interceptação e conversão de energia luminosa em tecido foliar (LEMAIRE, 2001).

\section{CONCLUSÃO}

Os rendimentos de forragem, taxa absoluta de crescimento, perfilhamento, número de folhas/perfilho, área foliar, tamanho médio de folhas e taxas de expansão e senescência foliar de $T$. vestitus são positivamente afetados pelas idades de rebrota. As taxas de crescimento da cultura, taxa de crescimento relativo e taxas de aparecimento de perfilhos e de folhas são inversamente proporcionais às idades de rebrota.

\section{REFERÊNCIAS}

BALLARÉ, C.L.; SÁNCHEZ，R.A.; SCOPEL，A.L.; CASAL, J.J.; GHERSA, C.M. Early detection of neighbor plants by phytochrome perception of spectral changes in reflected sunlight. Plant Cell and Environment, Oxford, v. 10, n. 7, p.551-557, 1987.

BRAGA, R.M. A agropecuária em Roraima: considerações históricas, de produção e geração de conhecimento. Boa Vista: Embrapa Roraima, 1998. 63p. (Embrapa Roraima. Documentos, 1).

CARRÈRE, P.; LOUAULT, F.; SOUSSANA, J.F. Tissue turnover within grass-clover mixed swards grazed by sheep: methodology for calculating growth, senescence and intake fluxes. Journal of Applied Ecology, v. 34, p.333-348, 1997.

COSTA, N. de L.; GIANLUPPI, V.; MORAES, A.; BENDAHAN, A.B. Produtividade de forragem e características morfogênicas e estruturais de Axonopus aureus nos cerrados de Roraima. Amazônia Ciência \& Desenvolvimento, Belém, v.6, n.12, p.41-56, 2011.

COSTA, N. de L.; MATTOS, P.S.R.; BENDAHAN, A.B.; BRAGA, R.M. Morfogênese de duas gramíneas forrageiras nativas dos lavrados de Roraima. Pubvet, Londrina, v.2, n.43, Art\#410, 2008 a.

COSTA, N. de L., PAULINO, V.T.; MAGALHÃES, J.A.; TOWNSEND, C.R.; PEREIRA, R.G.A. Morfogênese de gramíneas forrageiras na Amazônia Ocidental. Pubvet, Londrina, v.2, n.29, Art\#285, 2008 b.

CHAPMAN, D.F., LEMAIRE, G. Morphogenetic and structural determinants of plant regrowth after defoliation. In: BAKER, M.J. (Ed.). Grasslands for our world. Wellington: SIR Publishing, p.55-64, 1993.

GIANLUPPI, D.; GIANLUPPI, V.; SMIDERLE, O. Produção de pastagens no cerrado de Roraima. Boa Vista: Embrapa Roraima, 2001. 4p. (Embrapa Roraima. Comunicado Técnico, 14).

GOMIDE, J.A. Fisiologia do crescimento livre de plantas forrageiras. In: Pastagens: Fundamentos da Exploração Racional. Piracicaba: FEALQ. 1994. p.1-14.

GOMIDE, C.A.M.; GOMIDE, J.A.; PACIULLO, D.S.C. Morfogênese como ferramenta para o manejo de pastagens. Revista Brasileira de Zootecnia, v.35, supl. esp., p.554-579, 2006.

GRANT, S.A.; BERTHARM, G.T.; TORVELL, L. Components of regrowth in grazed and cut Lolium perenne swards. Grass and Forage Science, v.36, n.1, p.155-168, 1981.

HORST, G. L.; NELSON, C. J.; ASAY, K. H. Relationship of leaf elongation to forage yield of tall fescue genotypes. Crop Science, v.18, n.5, p.715-719, 1978.

LEITE, G.G.; GOMES, A.C.; NETO, R.T.; NETO, C.R.B. Expansão e senescência de folhas de gramíneas nativas dos cerrados submetidas à queima. Pasturas Tropicales, v.20, n.3, p.16-21, 1998.

LEMAIRE, G. Ecophysiology of grasslands: dynamic aspects of forage plant populations in grazed swards. In: GOMIDE, J.A.; MATTOS, W.R.S.; DA SILVA, S.C. (Eds.). INTERNATIONAL GRASSLAND CONGRESS, 19., São Pedro, 2001. Proceedings... São Pedro. Disponível em: <http://www.internationalgrasslands.org/publications> FEALQ, 2001. p. 29-37.

LEMAIRE, G.; AGNUSDEI, M. Leaf tissue turnover and efficiency of herbage utilization. In: LEMAIRE, G.; HODGSON, J.; MORAES, A.; CARVALHO, P.C.F.; NABINGER, C. (Eds). Grassland ecophysiology and grazing ecology. London: $\mathrm{CAB}$ International, 2000. p.265-288.

LEMAIRE, G.; CHAPMAN, D. Tissue flows in grazing plant communities. In: HODGSON, J.; ILLIUS, A.W. (Eds.). The ecology and management of grazing systems. Wallingford: CAB International, 1996. p.3-36.

MATA, D.; MORENO, E.; ROJAS, N.R. Efecto de la edad sobre la composición química del Trachypogon spp. en una sabana del Sureste del Estado Guarico. Zootecnia Tropical, v. 3, n. 1, p. 29-48, 1985.

MESQUITA, E.E.; NERES, M.A. Morfogênese e composição bromatológica de cultivares de Panicum maximum em função da adubação nitrogenada. Revista Brasileira de Saúde e Produção Animal, v.9, n.2, p.201- 
209, 2008.

MOCHIUTTI, S.; MEIRELLES, P.R.L.; SOUZA FILHO, A.P. Produção de matéria seca e rendimentos das espécies de uma pastagem nativa de cerrado do Amapá com a utilização de roçadeira. Macapá: Embrapa Amapá, 2000a. 15.p. (Embrapa Amapá. Documentos, 36).

MOCHIUTTI, S.; SOUZA FILHO, A.P.; MEIRELLES, P.R.L. Efeitos da queima sobre a produção total $\mathbf{e}$ rendimento das espécies em uma pastagem nativa de cerrado do Amapá. Macapá: Embrapa Amapá, 2000b. 14.p. (Embrapa Amapá. Documentos, 37).

PARSONS, A.J.; CHAPMAN, D.F. The principles of pasture growth and utilization. In: HOPKINS, A. (Ed.). Grass, its production and utilization. London: Blackwell Science, p.31-89, 2000.
SANTOS, M.E.R.; FONSECA, D.M.; BALBINO, E.M; SILVA, S.P.; MONNERAT, J.P.I.S.; GOMES, V.M. Características estruturais de perfilhos vegetativos e reprodutivos em pastos diferidos de capim-braquiária. Ciência Animal Brasileira, v. 11, n. 3, p.492-502, 2010.

TEJOS, R. Pastos nativos de sabanas inundables: caracterización y manejo. Barquisimeto, Venezuela: Megagraf, 2002. 111p.

TOWNSEND, C.R. Características produtivas de gramíneas nativas do gênero Paspalum, em resposta à disponibilidade de nitrogênio. Tese de Doutorado. Porto Alegre: UFRGS, 2008. 254p. Disponível em: 〈http://hdl.handle.net/10183/14799>.

TRINDADE, J.P.P.; ROCHA, M.G. Rebrotamento de capim caninha (Andropogon lateralis Nees.) sob efeito do fogo. Ciência Rural, v. 31, n. 6, p.1057-1061, 2001. 